\title{
Reuna
}

\section{MÍDIAS SOCIAIS PARA A GESTÃO DE PESSOAS E DE CONHECIMENTO EM RESTAURANTES DO NORDESTE DO BRASIL}

\section{SOCIAL MEDIA FOR THE MANAGEMENT OF PEOPLE AND KNOWLEDGE IN RESTAURANTS IN NORTHEAST BRAZIL}

\author{
http://dx.doi.org/10.21714/2179-8834/2019v24n2p1-20
}

\author{
Lydia Maria Pinto Brito \\ Universidade Potiguar, Brasil. \\ E-mail: lydiampbrito@yahoo.com.br \\ Mildred do Monte Damião Negreiros \\ Universidade Potiguar, Brasil. \\ E-mail: mildrednegreiros@unp.br
}

\author{
Ahiram Brunni Cartaxo de Castro Correio \\ Universidade Potiguar e Instituto Federal de Educação, Ciência e Tecnologia do Rio Grande do Norte \\ (IFRN), Brasil. \\ E-mail: brunnicastro@hotmail.com \\ Ismael de Mendonça Azevedo \\ Universidade Potiguar, Brasil. \\ E-mail: ismaeldemendonca@bol.com.br
}

Submissão: 03 Jul. 2018 Publicação: 05 Set. 2019. Sistema de avaliação: Double blind review. Centro Universitário UNA, Belo Horizonte - MG, Brasil. Editor geral: Prof. Dr. Gustavo Quiroga Souki

Este artigo encontra-se disponível nos seguintes endereços eletrônicos:

http://revistas.una.br/index.php/reuna/article/view/1035

http://dx.doi.org/10.21714/2179-8834/2019v24n2p1-20

\section{Resumo}

O estudo analisou a utilização do conteúdo de mídias sociais digitais para a gestão de pessoas e a gestão do conhecimento na percepção de gestores da área de alimentos do Nordeste do Brasil. Trata-se de uma pesquisa qualitativa básica com modo de investigação no estudo de múltiplos casos e de objetivo descritivo. Utilizouse de entrevista semiestruturada e análise documental para o levantamento dos dados. Os modelos estruturais da pesquisa foram o Diagnóstico de Gestão do Conhecimento proposto por Wendi Bukowitz e Ruth Williams, e o conteúdo teórico de Manuel Castells. O tratamento dos dados foi feito por meio de análise de conteúdo com o uso de planilhas eletrônicas. Os resultados evidenciam que: as redes sociais e as mídias sociais não são utilizadas para a gestão de pessoas e do conhecimento nos restaurantes investigados, nem no nível tático, para a resolução dos problemas do dia a dia de forma inovadora; nem no nível estratégico, que trata da aprendizagem e da construção do conhecimento que poderá manter as organizações viáveis no futuro.

Palavras-chave: Mídias sociais. Gestão de pessoas. Gestão do conhecimento. Restaurantes. Nordeste do Brasil. 


\section{ABSTRACT}

The study analyzed the use of digital social media content for people management and knowledge management in the perception of food managers in Northeast Brazil. It is a basic qualitative research with a mode of investigation in the study of multiple cases and a descriptive objective. A semi-structured interview and documentary analysis were used to collect the data. The structural models of the research were the Knowledge Management Diagnostics proposed by Wendi Bukowitz and Ruth Williams, and the theoretical content of Manuel Castells. The data treatment was done by means of content analysis with the use of spreadsheets. The results show that: social networks and social media are not used for the management of people and knowledge in the restaurants investigated, nor at the tactical level, for solving day to day problems in an innovative way; nor at the strategic level, which deals with learning and the construction of knowledge that can keep organizations viable in the future.

Keywords: Social media. People management. Knowledge management. Restaurants. Northeast of Brazil.

\section{Introdução}

A gestão estratégica centra-se no desempenho global e na utilização eficiente dos recursos, sendo esta abordagem muito sensível aos ambientes interno e externo das empresas, e pode ser interpretada como um conjunto de decisões gerenciais e ações de uma organização usadas para alcançar vantagem competitiva e desempenho superior de longo prazo sobre outras organizações (JASPER; ROSSAN, 2012). No campo de pesquisas sobre esta temática houve um esforço dos pesquisadores para ampliar a concordância sobre a definição ou conceito de estratégia ou gestão estratégica (GUERRAS-MARTíN; MADHOK; MONTOROSÁNCHEZ, 2014). Esses autores informam que os estudos de caso em profundidade têm sido amplamente substituídos pelo uso de ferramentas quantitativas baseadas no complexo de técnicas econométricas, análise multinível e, mais recentemente, uma mistura de metodologias, na qual um único estudo combina técnicas quantitativas e qualitativas.

Preponderantemente, as pesquisas sobre gestão estratégica são, segundo revisão preliminar e Guerras-Martín; Madhok; Montoro-Sánchez (2014), quantitativas e utilizam diversas técnicas e modelos estatísticos, principalmente a partir do ano de 2009. Nesse meio, complementam esses autores, as técnicas de análise multivariada de dados estão sendo amplamente utilizadas. Diante do exposto, este estudo consiste em responder a seguinte pergunta de pesquisa: como são desenvolvidas as pesquisas sobre gestão estratégica que utilizaram de técnicas de análise multivariada de dados? Assim, o objetivo deste trabalho é identificar e descrever a utilização de técnicas de análise multivariada de dados em pesquisas sobre gestão estratégica. Para tanto, foi utilizado uma revisão sistemática da literatura científica.

A revisão sistemática é uma revisão planejada para responder a uma pergunta específica e que utiliza métodos explícitos e sistemáticos para identificar, selecionar e avaliar criticamente os estudos, e para coletar e analisar os dados 
destes estudos incluídos na revisão (BOTELHO; MACEDO; FIALHO, 2010). Para tanto, este artigo está organizado além desta introdução, (i) revisão preliminar sobre pesquisas que tratam de revisões sobre o campo da gestão estratégica; (ii) apresentação dos procedimentos metodológicos de pesquisa; (iii) resultados e discussão e finalmente (iv) apresentação das conclusões.

\section{Referencial teórico}

As MSD e as RSD são muitas vezes confundidas na literatura, mas não são a mesma coisa. As MSD são os sites ou aplicativos de internet construídos para favorecer a criação do conhecimento de forma colaborativa (JUE; MARR; KASSOTAKIS, 2017), através da interação social (CASTELLS, 2017; 2015), e para o compartilhamento de informações em diversos formatos, como áudio, vídeo, texto, imagens, entre outros; e, para os mais diferentes usos, como por exemplo, para a identificação quase imediata da aceitação ou da rejeição de uma campanha ou de um produto (EGGERS et al., 2017).

Já as RSD, são as teias de relacionamentos formadas em canais da web que proporcionam a formação de comunidades on line e a interação de seus participantes ou usuários. Essas redes têm influenciado cada vez mais as novas gerações e na maneira como as pessoas se relacionam (CASTELLS, 2017, 2015). Entendem-se por RSD as páginas na internet que permitem a utilização de recursos com foco na interação, troca de informações, união de ideias em torno de valores e interesses compartilhados entre seus membros (JUE; MARR; KASSOTAKIS, 2017; WHELAN et al., 2016; MORGAND, 2016).

O conceito de redes é complexo e polissêmico (ZANCAN et al., 2012). O termo "redes" é derivado do latim e tem o significado de entrelaçamento de fios, cordas, arames, com aberturas fixadas por malhas, formando uma espécie de tecido (WHELAN et al., 2016). Já Nohria e Eccles (1992) analisam o termo "Redes Sociais" desde a sua origem, que é, segundo eles, proveniente da Sociologia, da Psicologia, da Biologia Molecular, da Teoria dos Sistemas, da Antropologia, entre outros. Para os autores, as redes têm como objetivos a interação, a ajuda mútua, o relacionamento, a integração e o compartilhamento entre os atores sociais.

Conforme Musso (2010), o termo rede passou por uma série de adaptações ao longo dos séculos, mas sua ruptura conceitual próxima do que é hoje ocorreu entre os séculos XVIII e XIX, quando passou de um estado natural para um estado artificial, ou seja, o conceito de rede começou a ser construído, uma vez que passou a ser pensado a partir de sua relação com o espaço. Nessa concepção, o movimento social se constitui mediante uma rede de interações informais, composta por uma pluralidade de atores (indivíduos, grupos, associações ou organizações) que se engajam em relações de conflito com oponentes claramente definidos e compartilham uma identidade coletiva distinta (MORGAND, 2016).

São várias as aplicações das RSD, entre elas tem-se: para mobilização social (GONÇALVES; FERRÃO; SOBRINHO, 2011), para a aprendizagem digital cooperativa (PARK et al., 2016), e-comerce (PARK; KIM, 2014), para a construção de perfis sociais e políticos (LUARN; YANG; CHIU, 2015), entre outros. 
No contexto das MSD e das RSD, a visibilidade social pode ser considerada como um fator que predispõe os usuários a emitirem opiniões, sejam de concordância ou não, com o seu grupo de relacionamento. Esses relatos pessoais passam a estabelecer influência direta na construção do conhecimento sobre determinados produtos, empresas e modelos de gestão, por exemplo. Quando isso ocorre, há uma propagação exponencial do conteúdo, gerando consequências de ganho ou perda da credibilidade na empresa e influência direta na sua imagem (MORGAND, 2016).

Atualmente, as redes mais conhecidas são o Facebook, o Twitter, o Instagram, o E-mail e o Youtube (ROBLES et al., 2015). Cada uma delas possui públicos bem distintos, com interesses diversos (RAUNIAR et al., 2014). Porém, para o mundo empresarial esses canais podem ser pessoas físicas, instituições ou empresas que queiram se comunicar com consumidores, fornecedores, parceiros e quem mais queira fazer parte (TEIXEIRA, 2013), por esse motivo é relevante discutir sobre gestão de pessoas e sobre a gestão do conhecimento, conforme em seguida.

\subsection{Gestão de pessoas e Gestão do Conhecimento}

Diante das mudanças ocorridas nas organizações, as maiores implicações envolvem a gestão de pessoas (GP) em sua complexa atividade que é gerenciar indivíduos em busca de resultados, pois "um dos papéis da gestão de Recursos Humanos $(\mathrm{GRH})$ é apoiar a organização na condução das dualidades subjacentes ao processo competitivo. O ambiente contemporâneo exige da GRH maior sofisticação para confrontar essas tensões" (BARROS; EVANS; PUCIK, 2007, p. 113).

As exigências impostas pelo cenário globalizado e competitivo impulsionaram as organizações a reverem seus diversos processos, dentre esses os de GP, ao ponto de entender que, o modelo centralizador utilizado nas últimas décadas, "caracterizado por ilhas de poder, nas quais cada grupo lutava para manter seus espaços, em completa desintegração de funções, e pela pouca influência nas decisões estratégicas, está com seus dias contados" (GRAMIGNA, 2007, p. 10), não subsiste mais na era da informação.

Nesse sentido, conforme Brito (2005), os novos modelos adequados ao atual ambiente das organizações - complexo, dinâmico e contraditório - de suporte para a GP são: a Gestão do Conhecimento, a Gestão de Competências e as Organizações de Aprendizagem. Esses modelos ressignificam os processos, os produtos, os serviços e as ações projetadas e implantadas nas dimensões das funções clássicas de RH (CASTRO; BRITO; VARELA, 2017), diga-se nos subsistemas de RH (Figura 1), que tem estreita relação com a utilização das RSD. 


\begin{tabular}{|c|c|c|}
\hline Internet & Gestão de pessoas & $\begin{array}{c}\text { Gestão do } \\
\text { conhecimento }\end{array}$ \\
\hline \multirow[t]{2}{*}{ Facebook } & $\begin{array}{c}\text { Planejamento / } \\
\text { Suprimento }\end{array}$ & Obtenção \\
\hline & Aplicação & Utilização \\
\hline \multirow[t]{2}{*}{ Twitter } & Capacitação & prendizagem \\
\hline & Desenvolvimento & Contribuição \\
\hline Instagram & $\begin{array}{l}\text { Avaliação de } \\
\text { Desempenho }\end{array}$ & Avaliação \\
\hline \multirow[t]{2}{*}{ E-mail } & Manutenção & $\begin{array}{l}\text { Construção / } \\
\text { Manutenção }\end{array}$ \\
\hline & Monitoração & Descarte \\
\hline
\end{tabular}

Figura 1. Interface entre as Redes Sociais Digitais, a Gestão de Pessoas e a Gestão do Conhecimento. Fonte: Elaborado pelos autores (2017).

A ressignificação da GP se tornou vital, pois passou a ter um papel ativo nas escolhas estratégicas das organizações, especialmente no tocante à preparação dos talentos para as mudanças (CASTRO; BRITO; VARELA, 2017; BAGNOLI; VEDOVATO, 2012).

Quadro 1. Ressignificação das funções clássicas de GP

\begin{tabular}{|c|c|}
\hline $\begin{array}{c}\text { Funções clássicas de RH } \\
\text { (subsistemas) }\end{array}$ & Ressignificação \\
\hline Planejamento & $\begin{array}{c}\text { Mapeamento interno e externo do conhecimento/ } \\
\text { competências necessárias para a empresa }\end{array}$ \\
\hline Suprimento (recrutamento e seleção) & Captação do conhecimento/ competências \\
\hline $\begin{array}{c}\text { Aplicação (cargos, carreira e } \\
\text { avaliação de desempenho) }\end{array}$ & $\begin{array}{c}\text { Aplicação do conhecimento/ competências individuais e } \\
\text { grupais ao negócio }\end{array}$ \\
\hline $\begin{array}{c}\text { Desenvolvimento (treinamento e } \\
\text { desenvolvimento) }\end{array}$ & $\begin{array}{c}\text { Disseminação do conhecimento/ competências, criação de } \\
\text { comunidades de aprendizagem, retenção do conhecimento } \\
\text { do trabalhador (propriedade intelectual) }\end{array}$ \\
\hline $\begin{array}{c}\text { Manutenção (salários, benefícios, } \\
\text { sauude e ocupacional) }\end{array}$ & $\begin{array}{r}\text { Recompensa pelo conhecimento/ competências } \\
\text { agregadoras de valor ao negócio }\end{array}$ \\
\hline Controle & $\begin{array}{c}\text { Monitoramento do processo mediante sistemas integrados } \\
\text { veiculadores de informações sobre os empregados }\end{array}$ \\
\hline
\end{tabular}

Fonte: Sistematizado de Castro, Brito e Varela (2017); Marques (2015) e Brito (2005).

A Figura 2, em seguida, demonstra como se dá a articulação do processo de Gestão de Competências, Gestão do Conhecimento e Organizações de Aprendizagem no contexto da ressignificação da gestão de pessoas. 


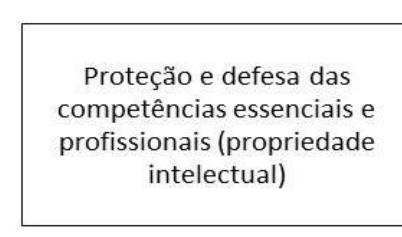

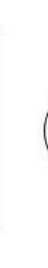
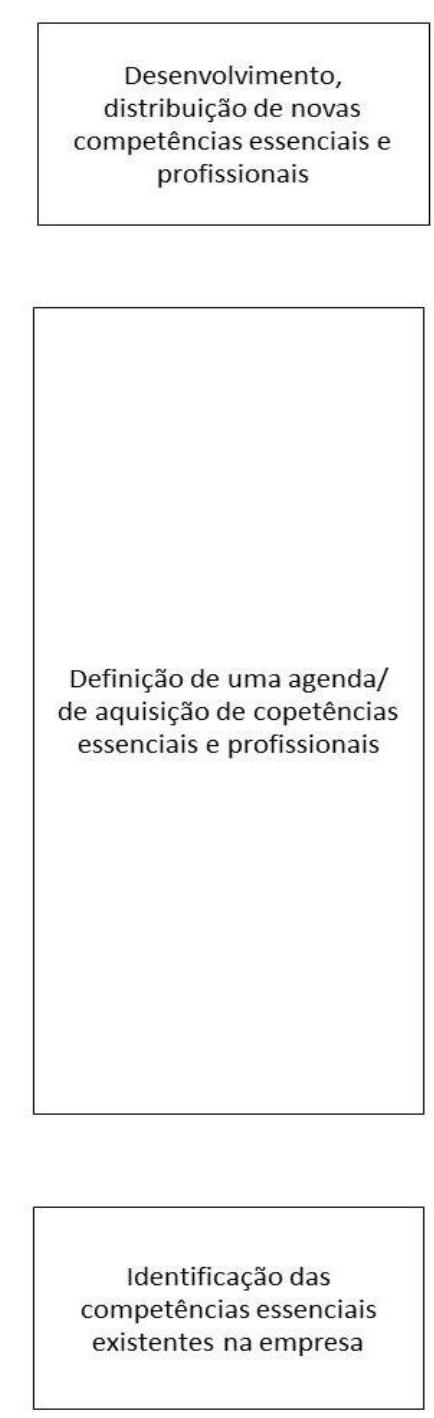

Articulação do processo de Gestão de Competências

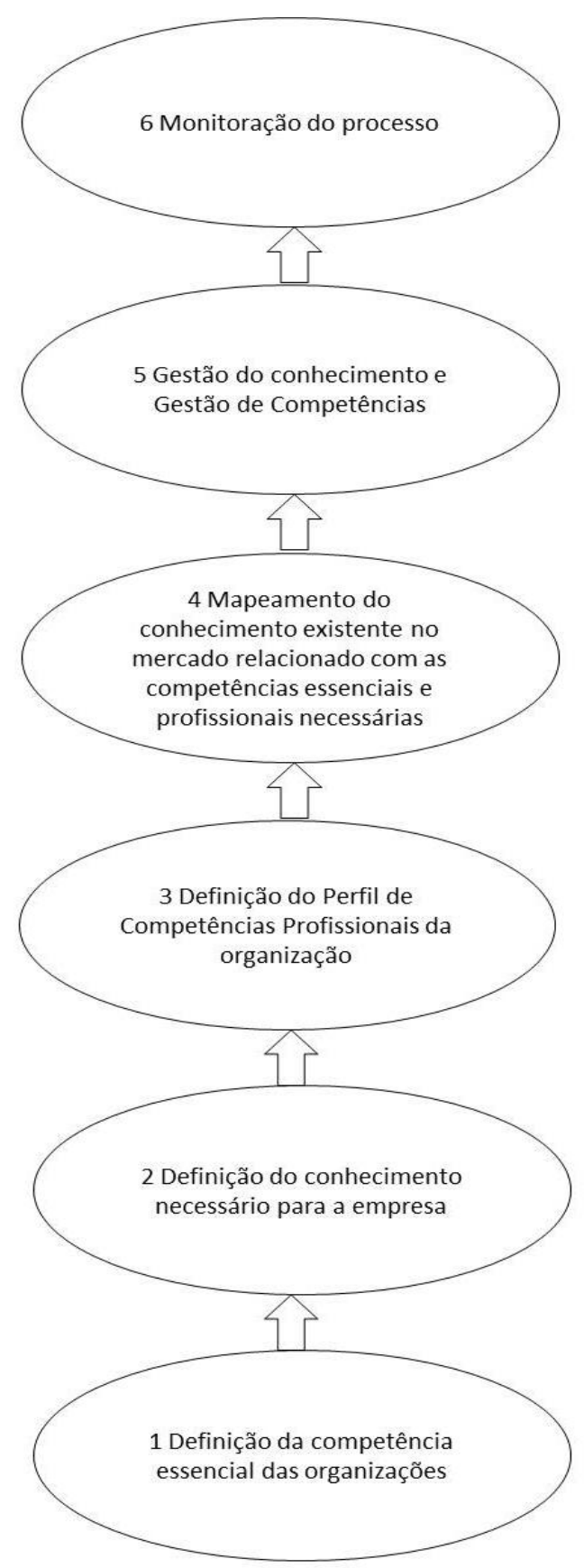

Gestão do Conhecimento nas organizações

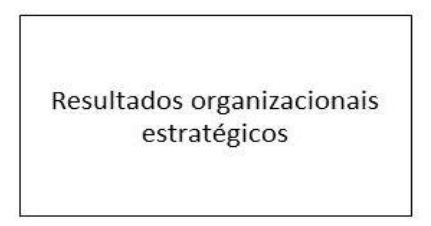

Captar, disseminar, criar, desenvolver, reter, recompensar, avaliare descartar o conhecimento
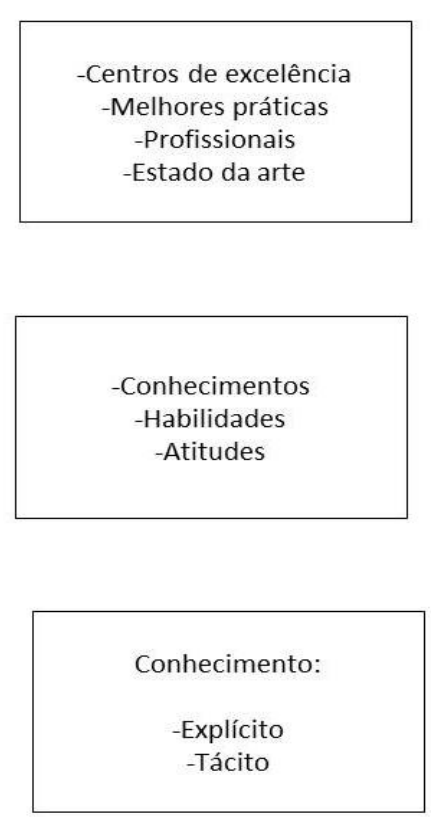

Missão/Negócio/Produto/In tenções estratégicas

Organizações de Aprendizagem

Figura 2. Articulação do processo de Gestão de Competências, Gestão do Conhecimento e Organizações de Aprendizagem. Fonte: Adaptado de Brito (2005, p. 109).

De modo geral, nesse novo contexto, conforme Freire et al. (2016) e Kianto et al. (2014), a educação para o trabalho se configura como a espinha dorsal da gestão do trabalho com pessoas tornando-se uma questão estratégica para as organizações, pois passa a ser o processo viabilizador para transformação do conhecimento tácito dos trabalhadores em conhecimento explícito, conforme o Quadro 3, o desenvolvedor das competências requeridas pelas organizações, e o fomentador da inovação contínua. 
Quadro 2. Dimensões do conhecimento, características e formas de aquisição.

\begin{tabular}{|c|c|}
\hline Conhecimento Explícito & Conhecimento Tácito \\
\hline $\begin{array}{l}\text { Características: articulado em linguagem formal, } \\
\text { codificada, estruturada, sistematizada, podendo } \\
\text { ser afirmações gramaticais, expressões } \\
\text { matemáticas, especificações, descrições, } \\
\text { manuais, banco de dados, comunicações visuais } \\
\text { e sonoras, e deve ser compreensível para } \\
\text { qualquer um que entende a simbologia na qual } \\
\text { ele é transmitido, podendo ser facilmente } \\
\text { comunicado, compartilhado e acessado. }\end{array}$ & $\begin{array}{l}\text { Características: conhecimento pessoal } \\
\text { incorporado à experiências de trabalho, às } \\
\text { habilidades, expertises, envolve fatores } \\
\text { intangíveis como crenças, valores, objetivos } \\
\text { pessoais, conclusões, insights, feeling, palpites } \\
\text { subjetivos, emoções, ideais, competências, } \\
\text { raciocínio, modelos mentais, ideias, opiniões, } \\
\text { intuição e criatividade. O conhecimento tático é } \\
\text { automático, oral e pode ser difícil comunica-lo. }\end{array}$ \\
\hline Forma de aquisição: educação formal & Forma de aquisição: experiência \\
\hline Formal & Não Formal \\
\hline
\end{tabular}

Fonte: Adaptado de Castro e Brito (2016, p. 305).

Além da ressignificação da área de gestão de pessoas, o papel das organizações ainda é o de promover condições facilitadoras para o desenvolvimento dos trabalhadores do conhecimento (CASTRO; BRITO; VARELA, 2017; NONAKA; TAKEUCHI, 2004), que podem ser viabilizadas, inclusive, pelas MSD e pelas RSD.

Assim, para se entender a gestão de pessoas na atualidade é importante a discussão sobre a gestão do conhecimento por meio dos movimentos sociais, demandas da sociedade, mudança social, mudança organizacional, organizações em rede, a web 2.0 e a comunicação (VON KROGH, 2012).

Nesse sentido, vários autores se revezaram ao longo do tempo, numa perspectiva do tipo evolutiva sobre a gestão do conhecimento nas organizações, mas a obra das autoras Bukowitz e Williams (2002) é a que apresenta uma metodologia que propõe um diagnóstico integrativo (LEE; KIM; KIM, 2012) para as organizações, compreendendo os processos táticos e estratégicos. Este diagnóstico está dividido em sete seções (obtenha, utilize, aprenda e contribua, avalie, construa e descarte) (Quadro 3). 
Quadro 3. Processos de gestão do conhecimento.

\begin{tabular}{|c|c|c|}
\hline Processos & Seções & Definição \\
\hline \multirow{4}{*}{ Táticos } & Obtenha & $\begin{array}{l}\text { Processo familiar que permite aos indivíduos, tomar decisões ou criar } \\
\text { produtos e serviços novos. Com o advento de novas tecnologias, é } \\
\text { enorme a quantidade de informação que flui para as organizações, } \\
\text { obrigando as pessoas a grande volume destas para obter aquela que é } \\
\text { indispensável para as suas necessidades. }\end{array}$ \\
\hline & Utilize & $\begin{array}{l}\text { Processo de utilização da informação de forma inovadora na } \\
\text { organização. Encorajando a criatividade, a experimentação e a } \\
\text { receptividade a novas ideias. }\end{array}$ \\
\hline & Aprenda & $\begin{array}{l}\text { Processo de reconhecimento da aprendizagem como um meio de criar } \\
\text { vantagem competitiva. O desafio está em encontrar maneiras de } \\
\text { integrar o processo de aprendizagem à maneira como as pessoas } \\
\text { trabalham. }\end{array}$ \\
\hline & Contribua & $\begin{array}{l}\text { Processo para garantir que as pessoas se sintam parte do sistema } \\
\text { gestor do conhecimento e incentivem a sua participação, dirimindo as } \\
\text { dúvidas quanto a riscos de compartilhar conhecimento com os demais. } \\
\text { Esta contribuição garante a criação de novos produtos e serviços na } \\
\text { organização. }\end{array}$ \\
\hline \multirow{3}{*}{ Estratégicos } & Avalie & $\begin{array}{l}\text { Processo que avalia quais os conhecimentos necessários na } \\
\text { organização e os compare com as necessidades futuras de } \\
\text { conhecimento. É preciso garantir que se tenha referência para } \\
\text { mensurar os ganhos com a gestão do conhecimento e investimentos } \\
\text { no capital intelectual. }\end{array}$ \\
\hline & $\begin{array}{l}\text { Construa/ } \\
\text { Mantenha }\end{array}$ & $\begin{array}{l}\text { Processo da gestão do conhecimento que assegura que o capital } \\
\text { intelectual futuro manterá a organização viável e competitiva. }\end{array}$ \\
\hline & Descarte & $\begin{array}{l}\text { Processo que identifica quanto o conhecimento não agrega mais valor } \\
\text { a organização ou que identifica quanto este descarte de conhecimento } \\
\text { irá gerar mais valor do que o manter apenas interno. }\end{array}$ \\
\hline
\end{tabular}

Fonte: Brito, Oliveira e Castro (2012); Bukowitz e Williams (2002).

Segundo Reginato e Graciolli (2012), a gestão do conhecimento, portanto, envolve experiências condensadas, valores, informação, incorporação de experiências, instintos, ideais, normas, procedimentos, sendo constituída de várias fases.

Pinho, Rego e Cunha (2012) colocam a GC como o conjunto de políticas de gestão que tem como finalidade favorecer a criação de conhecimento, sua transferência para todos os membros da organização e sua posterior aplicação, com vista a alcançar competências distintivas que podem dar às organizações uma diferenciação na sociedade.

Donate e Pablo (2015) colocam que GC envolve atividades de organização, estruturação e recuperação do conhecimento organizacional, e essas atividades permitem que as organizações mantenham uma memória organizacional que abrange o conhecimento que reside em várias formas, tais como a documentação escrita, as informações armazenadas em bancos de dados eletrônicos, conhecimento humano armazenado em sistemas especialistas e processos ou conhecimento tácito adquirido por indivíduos e redes de indivíduos. 
Sendo assim, tem-se que o conhecimento está muito próximo das ações organizacionais, causando impacto nas decisões, podendo proporcionar às organizações ganhos de eficiência mensurável em desenvolvimento de produtos/serviços e na produção, auxiliando o alcance das exigências de mercado.

Os autores Reginato e Graciolli (2012) destacam que a informação e o conhecimento adquiridos a partir da experiência dos empregados das organizações internamente ou no ambiente virtual, poderão ser combinados com a capacidade de inovação, pois a GC emerge na literatura como um modelo de gestão para melhorar a capacidade de inovação das organizações (DONATE; PABLO, 2015).

Em seguida, tem-se a descrição dos procedimentos metodológicos que viabilizaram a pesquisa.

\section{Metodologia de pesquisa}

Trata-se de uma pesquisa qualitativa básica (MERRIAM, 1998). Quanto ao modo de investigação é um estudo de múltiplos casos (YIN, 2015), e quanto aos procedimentos trata-se de uma pesquisa descritiva e exploratória. (CERVO; BERVIAN; DA SILVA, 2007).

Como local de aplicação da pesquisa, foram escolhidos 10 restaurantes da cidade do Natal/RN (Quadro 4). Estas empresas foram escolhidas devido à conveniência dos pesquisadores (COOPER; SCHINDLER, 2016). Assim, a pesquisa foi destinada aos gestores de restaurantes de referência da cidade que trabalham com comidas típicas da região e que tiveram sua origem na própria cidade do Natal/RN.

Quadro 4. Sujeitos da pesquisa

\begin{tabular}{|c|c|c|}
\hline \multirow{2}{*}{ Empresa } & \multicolumn{2}{|c|}{ Sujeitos da pesquisa } \\
\cline { 2 - 3 } & Serviço & Gestor \\
\hline Restaurante 1 & Massas & 1 \\
\hline Restaurante 2 & Food truck & 1 \\
\hline Restaurante 3 & Food truck & 1 \\
\hline Restaurante 4 & A la carte & 1 \\
\hline Restaurante 5 & A la carte & 1 \\
\hline Restaurante 6 & A la carte & 1 \\
\hline Restaurante 7 & Self service & 1 \\
\hline Restaurante 8 & Self service & 1 \\
\hline Restaurante 9 & Self service & 1 \\
\hline Restaurante 10 & Food truck & 1 \\
\hline
\end{tabular}

Fonte: Dados da pesquisa (2017).

A pesquisa foi viabilizada por meio de entrevistas semiestruturadas (GASKELL, 2002). O plano de coleta de dados e o desenvolvimento da pesquisa foram compostos pelos seguintes passos: a) contato com as empresas e explicação da pesquisa; b) aplicação do instrumento de coleta de dados, a partir de entrevista; 
c) organização dos dados; d) análise dos dados; e) elaboração dos resultados e conclusão.

O roteiro de entrevistas foi dividido em três blocos. O primeiro bloco é formado por perguntas sobre o uso das mídias sociais digitais pelos gestores das empresas de restauração; o segundo, com perguntas sobre o processo tático da gestão do conhecimento na perspectiva dos gestores a partir do modelo de Bukowitz e Williams (2002); e o terceiro, abrange a apropriação do conhecimento através das mídias sociais no processo estratégico.

Nas entrevistas, para facilitar a materialização da gestão de pessoas e do conhecimento, utilizou-se algumas perguntas sobre os movimentos sociais que ocorreram recentemente no Brasil e no mundo, extraídas da literatura produzida por Castells $(2017 ; 2015)$.

O tratamento dos dados ocorreu por meio de análise de conteúdo (Bardin, 2009). Os quadros de categorização foram construídos através da condensação de respostas semelhantes na análise das transcrições das entrevistas. Essa condensação ocorreu por meio do encontro de categorias comuns, denominadas de categorias de análise, conforme o quadro 5.

Quadro 5. Categorias de análise e atributos da pesquisa

\begin{tabular}{|c|c|c|c|c|}
\hline Categorias & Teórico & Conceito & Atributos & Questões \\
\hline \multirow{3}{*}{ A. Redes sociais } & \multirow{3}{*}{$\begin{array}{l}\text { Johnson } \\
\text { (2009) }\end{array}$} & \multirow{3}{*}{$\begin{array}{l}\text { Conjunto de unidades e as relações que acontecem entre } \\
\text { elas. Representando o capital social de um indivíduo. }\end{array}$} & Email & \multirow{3}{*}{ Bloco 1} \\
\hline & & & $\begin{array}{l}\text { Facebook } \\
\text { Twilter }\end{array}$ & \\
\hline & & & Instagram & \\
\hline \multirow{7}{*}{$\begin{array}{l}\text { B. gestão de } \\
\text { pessoas }\end{array}$} & \multirow{7}{*}{$\begin{array}{l}\text { Scumparim } \\
\text { et. al. } \\
\text { (2011) }\end{array}$} & \multirow{7}{*}{$\begin{array}{l}\text { Gestão que cuida das relações com os colaboradores, } \\
\text { preocupando-se com produção, custos, competitividade, } \\
\text { qualidade de vida, motivação, suprimento, aplicação, } \\
\text { capacitação, desenvolvimento, avaliação, manutenção, } \\
\text { monitoração, dentre outros fatores. }\end{array}$} & Suprimento & \multirow{4}{*}{ Bloco 2} \\
\hline & & & Aplicação & \\
\hline & & & Capacitação & \\
\hline & & & Desenvolvimento & \\
\hline & & & Avaliação & \multirow{3}{*}{ Bloco 2} \\
\hline & & & Manutenção & \\
\hline & & & Monitoração & \\
\hline \multirow{7}{*}{$\begin{array}{l}\text { C. gestão do } \\
\text { conhecimento }\end{array}$} & \multirow{7}{*}{ Brito (2005) } & \multirow{7}{*}{$\begin{array}{l}\text { Capacidade desenvolvida pelas organizações de mapear na } \\
\text { sociedade e trazer para o contexto institucional a distribuição, } \\
\text { criação, recompensa e retenção de conhecimento } \\
\text { relacionado à atividade fim. }\end{array}$} & Obtenção & \multirow{4}{*}{ Bloco 3} \\
\hline & & & Utilização & \\
\hline & & & Aprendizagem & \\
\hline & & & Contribuição & \\
\hline & & & Avaliação & \multirow{3}{*}{ Bloco 3} \\
\hline & & & Construção / Manutenção & \\
\hline & & & Descarte & \\
\hline
\end{tabular}

Fonte: Elaborado pelos autores (2017).

A validade e a confiabilidade interna da pesquisa foram aferidas por meio da avaliação de pares pesquisadores da área. A validade externa da pesquisa está na descrição rica e densa que buscou compreender em profundidade a percepção de um grupo de sujeitos, evitando-se formas de generalização dos achados para a população (MERRIAM, 1998). 


\section{Discussão dos resultados}

\subsection{Caracterização da utilização das mídias sociais nas empresas estudadas}

Quanto ao uso de computadores (desktop), as 10 empresas possuem o equipamento e fazem uso do mesmo para execução de planilhas de compra e venda, pedidos, controle de estoque e fornecimento. Os notebooks, tablets e smartphones são de propriedades dos próprios gestores e usados por todos como ferramenta particular, dentro e fora da empresa. Quando necessário, entram em contato com algum fornecedor ou resolvem alguma urgência referente à empresa através da ferramenta em questão. Assim, confirmamos a ideia de que a internet tem um papel importante no funcionamento e mudanças dentro das empresas (TEIXEIRA, 2013).

Todas as empresas de alimentos e bebidas estudadas demonstraram que utilizam a internet como uma importante ferramenta para desenvolver suas tarefas, que o uso dela é constante, tanto para pesquisas de mercado como para divulgação de mercadoria, ou seja, para marketing e propaganda. Assim, como diz Teixeira (2013), para algumas organizações, tal processo é feito com criação de login e postagem de mensagens, promoções ou propagandas.

A utilização das mídias sociais nas empresas estudadas é descrita a partir da seguinte análise: das 10 empresas estudadas, todas fazem uso das redes sociais $\mathrm{E}$ mail, Facebook e Instagram, as utilizando para fins pessoais, comércio e marketing da empresa. Estão sempre conectados em seus computadores particulares ou da empresa (notebooks) e, principalmente, nos smartphones. Como aponta Castells (2017), os empregados das empresas seguem tendências da sociedade, quanto ao acesso de mídias sociais.

Perguntado aos gestores sobre o uso de Twitter, Linkedin, Badoo, Skype, Lulu e jogos virtuais, nenhum gestor afirmou que fazia uso destas ferramentas da internet. Os portais e as universidades corporativas também não são focos de acesso no ramo de alimentação.

Quanto ao resultado sobre as comunidades virtuais, as 10 empresas pesquisadas não utilizam essas comunidades, sendo este resultado incompatível com os da pesquisa de Jue, Marr e Kassotakis (2017).

Quanto ao uso de lan house, não ficou demonstrado que os gestores fazem o uso deste tipo de ambiente para aceso à internet, pois eles possuíam seus próprios equipamentos de conexão com a web. Além disso, 100\% dos gestores passam todo o seu tempo conectados às mídias sociais, sejam elas sites de pesquisas ou de relacionamentos. Esses dados corroboram com Castells (2015) e Teixeira (2013), quando atestam para a propagação do uso das redes sociais como parte da atividade diária das pessoas e das organizações.

Nas 10 empresas estudadas, foi observado que os 10 de gestores de alimentos e bebidas eram do sexo masculino, tinham idade entre 25 e 45 anos. Sendo dessa forma, gestores jovens, todos muitos atentos às mídias sociais e a tudo que a internet the proporciona. São gestores com escolaridade de nível superior completa que, assim como fala Teixeira (2013), a comunicação estabelecida nas redes sociais, no que diz respeito à estratégica adotada, o mapeamento do público e 
o estreitamento da relação, também é identidade, que quando bem feita, gera uma boa imagem para a organização.

No quadro 6, em seguida, estão descritas as análises qualitativas da utilização das mídias sociais das empresas estudadas, resultantes do seguinte questionamento: como se sente quando não está conectado?

Quadro 6. Como se sente quando não está conectado?

\begin{tabular}{|l|l|}
\hline Categoria & Fragmentos da fala \\
\hline Preocupados & $\begin{array}{l}\text { "Porque quase todas as atividade que realizo dependem da } \\
\text { internet". }\end{array}$ \\
\hline Incapazes & "Sem o uso da internet fico incapaz de fazer qualquer ação". \\
\hline Incompletos & $\begin{array}{l}\text { "A internet já faz parte do cotidiano de todos nós, sem ela fica tudo } \\
\text { incompleto". }\end{array}$ \\
\hline Improdutivos & $\begin{array}{l}\text { "A internet é fundamental para desenvolvimento de qualquer } \\
\text { empresa. Sem ela estamos sendo improdutivos com o mercado e } \\
\text { perdendo para este". }\end{array}$ \\
\hline Atrasados & $\begin{array}{l}\text { "Diante de uma tecnologia tão avançado é necessário esta sempre } \\
\text { conectado. Sem a Internet fica a sensação de não estar conectado } \\
\text { ao mundo, e com isso esta atrasado diante dele". }\end{array}$ \\
\hline
\end{tabular}

Fonte: Dados da pesquisa.

A análise dos dados obtidos no Quadro 6, com relação ao sentimento de quando não estão conectados, está relacionado a algo negativo tanto no âmbito pessoal com profissional. Os gestores sentem-se preocupados, incapazes, incompletos, improdutivos e atrasados quando não estão conectados à rede. Corroborando com o pensamento de Rauniar et al. (2014), pois nota-se, dessa forma, uma dependência dos gestores com as redes.

O Quadro 7 mostra que, para o cliente há toda uma disponibilidade e facilidade do uso da internet, o gerente diz que: "quanto mais negócios o cliente ficar resolvendo em seu restaurante mais ele dá lucro ao seu estabelecimento". 
Quadro 7. É viável disponibilizar wi-fi para os clientes da empresa?

\begin{tabular}{|l|l|}
\hline Categoria & Fragmento da fala \\
\hline Necessidade Básica & $\begin{array}{l}\text { "Ter internet com wi-fi para seus clientes em um } \\
\text { restaurante, deixou de ser um acessório de diferenciação e } \\
\text { passou a ser uma necessidade. Muitos clientes vão ao } \\
\text { restaurante para resolver negócios e necessitam da } \\
\text { internet". }\end{array}$ \\
\hline $\begin{array}{l}\text { Tendência } \\
\text { Mercado }\end{array}$ & $\begin{array}{l}\text { "É uma tendência normal de todos os estabelecimentos } \\
\text { oferecem wi-fi para seus clientes". }\end{array}$ \\
\hline Modo de Fidelização & $\begin{array}{l}\text { "Quando o cliente tem acesso a internet ele se sente } \\
\text { melhor e procura o restaurante que oferece este serviço". }\end{array}$ \\
\hline
\end{tabular}

Fonte: Dados da pesquisa.

Portanto, a disponibilização de wi-fi aos clientes se tornou uma necessidade básica para a empresa, que pode ser visto pelo lado financeiro, deixando de ser uma diferenciação de mercado e tornando-se uma tendência em todos os estabelecimentos, com vistas à fidelização de seus clientes, uma vez que muitos deles vão ao restaurante para resolver negócios e necessitam da internet. Por outro lado, sobre a disponibilização de wi-fi para os funcionários, foi unanimidade a concordância entre os gestores de que o uso dos dispositivos pessoais pelos empregados traz problemas à produtividade, pois tira o foco do trabalho, além de contaminar os alimentos e distrair a "brigada".

\subsection{Processo tático de gestão de pessoas e da gestão do conhecimento}

Quanto ao Diagnóstico de Gestão do Conhecimento nos processos táticos, tem-se os seguintes resultados:

- Suprir/Obter: considerando a questão de como a empresa capta conhecimentos das mídias sociais para o planejamento, suprimento de pessoas e obtenção de conhecimento, observa-se que: as empresas estudadas foram unanimidade em dizer que não captam conhecimentos através de mídias sociais para planejamento, suprimento de pessoas e obtenção de conhecimentos.

As empresas pesquisadas têm recursos de acessos à internet para comunicação através de diversos meios, mas não os usa para o planejamento estratégico nem o operacional; não utilizam a rede para captar informações sobre clientes e mercado. As pessoas interessadas em uma vaga de emprego, chegam a mandar currículo via internet, porém não são aproveitados, só sendo, realmente aproveitados, aqueles que por indicação são selecionados. 
Além disso, não percebido nas organizações pesquisadas qualquer política de gestão de pessoas ou de conhecimento que utilize informações fornecidas pela sociedade através das redes sociais. Os achados, nesse caso não corroboram com Jue, Marr e Kassotakis (2017), quando argumentam que as mídias sociais aceleram o desenvolvimento do conhecimento coletivo dentro das organizações, possibilitando esse poder de conexão entre indivíduo com conhecimento, aparentemente irrelevantes.

- Aplicar/Utilizar: Para a questão de como a empresa capta conhecimentos nas mídias sociais para seu processo de socialização e ingresso no cargo/carreira e melhor utilização do conhecimento relacionado ao seu negócio, verificou-se que, segundo os gestores que as MSD não são utilizadas para formação de seus quadros de funcionários.

Assim, a pesquisa mostrou que as mídias sociais não tem influência na socialização de novos talentos para o serviço de restauração no Nordeste do Brasil.

- Capacitar/Aprender: Verificando-se a questão de como a empresa capta conhecimentos através do uso corporativo das mídias sociais para seu processo de capacitação e para o desenvolvimento do conhecimento relacionado ao seu ramo de negócio; os gestores não demonstraram conhecimento ou interesse em fazê-lo.

Essa atitude vai de encontro ao proposto por Freire et al. (2016) e Kianto et al. (2014) que colocam a capacitação como a espinha dorsal dos novos modelos de gestão, sendo necessário para a aquisição de habilidades, regras, conceitos que, consequentemente, resultam em uma melhor adequação dos empregados às necessidades apontadas pelos empregadores.

Em outras palavras, a capacitação através de mídias sociais na área de alimentos e bebidas não é apresentada aos funcionários. Quando um membro da brigada sente necessidade de um curso procura fazer por sua conta, focado em suas necessidades. O gestor não capta nenhum conhecimento para sua brigada, seja para capacitação, para melhorar conhecimentos ou melhorar o desempenho de seu funcionário através de redes sociais. Tais resultados levantam a necessidade da ampliação e o desenvolvimento das competências dos empregados, através de uma aprendizagem continuada. Afinal, a aprendizagem é importante para a organização porque, junto com a contribuição, ela é o passo de transição entre a aplicação de ideias e a geração de ideias novas (BUKOWITZ; WILLIAMS, 2002).

- Desenvolver/Contribuir: Na questão em que foi perguntado como a empresa capta conhecimentos das mídias sociais para melhorar a contribuição de seus empregados para a organização, observou-se que, pouco é captado através da internet, pois os gestores consideraram a internet como um meio muito moderno e que pouco contribui para desenvolver a área de alimentos e bebidas.

Uma justificativa para a não aplicação deste processo pode ser encontrada em Bukowitz e Williams (2002). Segundos as autoras, o desenvolvimento/contribuição é um passo do processo que a maioria das organizações caracteriza como difícil de realizar. Contudo, quando implementado proporciona a geração de ideias úteis e inovadoras que podem propiciar a criação de algo novo e útil às organizações. 


\subsection{Processo estratégico da gestão de pessoas e da gestão do conhecimento}

Os resultados do diagnóstico de Gestão do Conhecimento no processo estratégico apontaram que:

- Avaliar/Avaliar: Passando para o processo estratégico, verifica-se como as empresas captam conhecimentos das mídias sociais para enriquecimento do processo avaliativo de seus funcionários e de seu processo de gerenciamento do conhecimento. Segundo Bukowitz e Williams (2002), o processo de avaliação contínua é necessário até mesmo para que se possa comparar o capital existente com as necessidades que possam vir a aparecer ao longo do tempo.

Todavia, os relatos dos gestores foram de que não usam mídias sociais para realização do processo avaliativo de seus funcionários. A maioria segue seus funcionários no Facebook apenas para "acompanhamento pessoal". Nesse sentido, observa-se que os gestores perdem a oportunidade de avaliar o capital intelectual da organização e as competências dos empregados pessoal por meio das MSD.

- Manter/Construir: Este processo, segundo Bukowitz e Williams (2002), assegura que o futuro conhecimento mantenha a organização viável e/ou competitiva. Ou seja, exige um olhar renovado sobre a capacidade de gerenciar. Para tanto, é necessário que a companhia estabeleça relacionamento com clientes, fornecedores e até mesmo empregados, de modo a construir conhecimento sobre o mercado.

Em se tratando de como a empresa capta conhecimentos das mídias sociais para manter o capital humano e conhecimento dentro da organização, os respondentes que a manutenção e a construção das brigadas ainda são feitas através do "olho", esvaindo-se a oportunidade de ter as redes sociais digitais como aliadas nesse processo.

- Monitorar/Descartar: Foi perguntado aos gestores como a empresa toma por base as mídias sociais para descartar conhecimento e desligar pessoas da organização. Segundo os gestores, o descarte também não usa das RSD e das MSD.

Esse resultado demonstra que os registros de monitoramento e o consequente descarte não serão acompanhados de forma sistemática pela organização.

Bukowitz e Williams (2002) sugerem a utilização de um instrumento qualitativo, o qual tem como objetivo a introspecção e a reflexão dos assuntos e preocupações que cercam a gestão de pessoas e do conhecimento nas organizações. Ao fim destes resultados, o que se pode observar é que, em geral, nas empresas de alimentos e bebidas, todo o processo de gestão de pessoas e de gestão do conhecimento não faz uso de mídias sociais.

\section{Considerações finais}

Esta seção sistematiza os resultados depreendidos da análise dos dados coletados nas empresas de alimentos e bebidas da cidade do Natal/RN, quanto ao uso corporativo das mídias sociais digitais para a gestão de pessoas e gestão do conhecimento.

REUNA, Belo Horizonte - MG, Brasil, v.24, n.I, p.I-2D, Jan. - Mar. 2019 - ISSN 2179-8834 
No percurso investigativo, observou-se que a interação entre as pessoas, notadamente no campo digital, tem sido cada vez mais estudada em função do advento das redes sociais digitais, pois as mídias sociais constituem uma estrutura comunicacional importante para a exportação dos pontos de vista e para o surgimento de outros argumentos. Trata-se de uma arena em que todos têm a oportunidade de visualização dos fatos e opiniões, além de ser a responsável pela manutenção constante de ciclos de debates, até que se chegue ao entendimento acerca de um problema de interesse geral.

Nesse sentido, com relação ao uso das mídias sociais em si, os resultados demonstraram que os gestores das empresas de restauração as utilizam de forma ampla, inclusive para uso pessoal. Evidencia-se, ainda, que todos os sujeitos investigados possuem computadores, notebooks ou tablets, sendo esses utilizados para acessar os e-mails, págnias de Facebook, o Whatsapp e ao Instagram. Ou seja, os gestores estão conectados estabelecendo interação e troca de ideias com pessoas ou grupos e expondo as suas opiniões. Além disso, seus restaurantes estão conectados à internet e esta rede está à disposição de seus clientes através de wi-fi como uma forma de mantê-los (os clientes) em consumo nos estabelecimentos.

Entretanto, observou-se que as empresas pesquisadas da área de alimentação e bebidas da cidade do Natal/RN, não fazem uso de mídias sociais para a gestão de pessoas e para a gestão do conhecimento, resultados semelhantes aos encontrados por Perez-Soltero et al. (2013) no noroeste do México.

O estudo revelou também que, em nenhum dos restaurantes investigados são utilizadas mídias sociais para realizar captação de pessoas. Os processos de gestão de pessoas - recrutamento, desenvolvimento, capacitação e manutenção dos funcionários -, nas empresas de restauração, não se efetivam através da internet, sendo contratados os seus funcionários via indicação. Nessa direção, apesar do uso crescente dos canais digitais para atrações de talentos, as empresas aqui estudadas ainda proíbem o uso de mídias sociais durante a jornada de trabalho, alegando a violação de privacidade, a perda de foco e a queda de produtividade dos funcionários, sendo esses os principais receios apontados.

Considerando-se que o estudo foi realizado em microempresas e em empresas de pequeno porte da cidade do Natal, fundadas na própria cidade, suas descobertas não podem ser inferidas em outros contextos. Algumas questões ficaram pendentes para investigações futuras, por exemplo: qual o significado e o resultado da exclusão dos empregados das mídias sociais e das redes sociais para o ramo de restauração? Qual a consequência do não uso da gestão do conhecimento para o turismo regional? Além disso, outros estudos podem ser feitos para a ampliação do campo de estudo, com organizações de restauração de médio e grande porte e estudos comparativos. 


\section{Referências}

ASSOCIAÇÃO BRASILEIRA DAS INDÚSTRIAS DA ALIMENTAÇÃO. Relatório Anual. $2017 . \quad$ Disponível em: <https://www.abia.org.br/vsn/temp/z201843relatorioABIA2017.pdf>. Acesso em 20 fev. 2018.

BAGNOLI, Carlo; VEDOVATO, Marco. The impact of knowledge management and strategy configuration coherence on SME performance. Journal of Management \& Governance, v. 18, n. 2, p. 615-647, 2014.

BARDIN, Lawrence. Análise de conteúdo. Lisboa: edições, 70, 2009.

BARROS, Betânia T. de; EVANS, Paul; PUCIK, Vladimir. A gestão de pessoas no Brasil: virtudes e pecados capitais. Elsevier Editora, 2007.

BUKOWITZ, Wendi R.; WILLIAMS, Ruth L. Manual de gestão do conhecimento: ferramentas e técnicas que criam valor para a empresa. Bookman, 2002.

BRITO, Lydia M. P.; OLIVEIRA, Patrícia W. S. de; CASTRO, Ahiram B. C. de. Gestão do conhecimento numa instituição pública de assistência técnica e extensão rural do Nordeste do Brasil. Revista de Administração Pública, v. 46, n. 5, p. 13411366, 2012. DOI: 10.1590/S0034-76122012000500008.

Gestão de competências, gestão do conhecimento e organizações de aprendizagem: instrumentos de apropriação pelo capital do saber do trabalhador. Fortaleza: Imprensa da Universidade Federal do Ceará, 2005.

CASTELLS, Manuel. Redes de indignação e esperança: movimentos sociais na era da internet. Zahar, 2017.

. Networks of outrage and hope: Social movements in the Internet age. John Wiley \& Sons, 2015.

CASTRO, Ahiram. B. C. de; BRITO, Lydia M. P. Como o IFRN/Campus são Paulo do Potengi aprende? CASTRO, Ahiram. B. C. de; LIMA, José G. S. A. de; AQUINO, Maria E. S. P. de; SILVA, U. R. de L. (Org.). Práticas educativas em movimento: experiências formativas de ensino, pesquisa, extensão e gestão no Campus São Paulo do Potengi do IFRN. Natal: IFRN Editora, 2016.

; VARELA, Jedídija $H$. de $S$. A ressignificação da área de gestão de pessoas e os novos papéis das pessoas e das organizações. HOLOS, n. 4, p. 408423, 2017. DOI: 10.15628/holos.2017.5168.

CERVO, Amado L.; BERVIAN, Pedro A.; DA SILVA, Roberto. Metodologia Científica. São Paulo: Pretence Hall, 2007.

COOPER, Donald R.; SCHINDLER, Pamela S. Métodos de Pesquisa em Administração. 12a Edição. McGraw Hill Brasil, 2016. 
DONATE, Mario J.; DE PABLO, Jesús D. Sánchez. The role of knowledge-oriented leadership in knowledge management practices and innovation. Journal of Business Research, v. 68, n. 2, p. 360-370, 2015. DOI: 10.1016/j.jbusres.2014.06.022.

EGGERS, Fabian et al. Technologies that support marketing and market development in SMEs-Evidence from social networks. Journal of Small Business Management, v. 55, n. 2, p. 270-302, 2017. DOI: 10.1111/jsbm.12313.

FREIRE, Patricia de S. et al. Universidade Corporativa em Rede: Considerações Iniciais para um Novo Modelo de Educação Corporativa. Revista ESPACIOS, v. 37, n. 5, 2016.

GASKELL, George. Entrevistas individuais e grupais. In: BAUER, M. W.; GASKELL, G. Pesquisa qualitativa com texto, imagem e som - Um manual prático. 5 ${ }^{\text {a }} \mathrm{Ed}$. Petrópolis, RJ: Vozes, 2002.

GONÇALVES, Caio M.; FERRÃO, André M. de A.; SOBRINHO, Fuad G. Model of social mobilization for the revitalisation of civil enterprises, of complex social networks, and of regional development. Journal of Integrated Design and Process Science, v. 15, n. 5, p. 27-38, 2011. DOI: 10.3233/jid-2012-0104.

GRAMIGNA, Maria R. Modelo de competências e gestão dos talentos. 2a․ Ed. São Paulo: Pearson Prentice Hall, 2007.

JUE, Arthur L.; MARR, Jackie A.; Kassotakis, Mary E. Mídias sociais nas empresas: colaboração, inovação, competitividade e resultados. São Paulo: Évora, 2017.

KIANTO, Aino et al. The interaction of intellectual capital assets and knowledge management practices in organizational value creation. Journal of Intellectual capital, v. 15, n. 3, p. 362-375, 2014. DOI: 10.1108/JIC-05-2014-0059.

LEE, Sangjae; GON KIM, Byung; KIM, Hoyal. An integrated view of knowledge management for performance. Journal of Knowledge management, v. 16, n. 2, p. 183-203, 2012. DOI: 10.1108/13673271211218807.

LUARN, Pin; YANG, Jen-Chieh; CHIU, Yu-Ping. Why people check in to social network sites. International Journal of Electronic Commerce, v. 19, n. 4, p. 21-46, 2015. DOI: 10.1080/10864415.2015.1029353.

MARQUES, Fernanda. Gestão de Pessoas: fundamentos e tendências. Brasília: DDG/ENAP, 2015.

MERRIAM, Sharan B. Qualitative Research and Case Study Applications in Education. San Francisco: Jossey-Bass, 1998. 
MORGAND, A. Cooperation transformed by digital social network initiative. Revue Francaise de Gestion, v. 6, n. 259, p. 155-170, 2016.

MUSSO, P. A filosofia da rede. In: PARENTE, A. (Org.). Tramas da rede: novas dimensões filosóficas, estéticas e políticas da comunicação. 2a․ ed. Porto Alegre: Sulina, 2010.

NONAKA, Ikujiro; TAKEUCHI, Hirotaka. Criação de conhecimento na empresa. Elsevier Brasil, 2004.

NOHRIA, Nitin. Networks and organizations: structure, form and action. 1994.

PARK, Jeongbae et al. A method for measuring cooperative activities in a social network supported learning environment. Wireless Personal Communications, v. 89 , n. 3, p. 863-879, 2016. DOI: 10.1007/s1127.

PARK, Hyejune; KIM, Youn-Kyung. The role of social network websites in the consumer-brand relationship. Journal of Retailing and Consumer Services, v. 21, n. 4, p. 460-467, 2014. DOI: 10.1016/j.jretconser.2014.03.011.

PEREZ-SOLTERO, Alonso et al. A diagnostic of knowledge management processes at the restaurant industry SMEs to identify improvements at their productive processes. Intangible Capital, v. 9, n. 1, p. 153-183, 2013. DOI: 10.3926/ic.381.

PINHO, Isabel; REGO, Arménio; CUNHA, Miguel P. e. Improving knowledge management processes: a hybrid positive approach. Journal of knowledge management, v. 16, n. 2, p. 215-242, 2012. DOI: 10.1108/13673271211218834.

RAUNIAR, Rupak et al. Technology acceptance model (TAM) and social media usage: an empirical study on Facebook. Journal of Enterprise Information Management, v. 27, n. 1, p. 6-30, 2014. DOI: 10.1108/JEIM-04-2012-0011.

REGINATO, Carlos. E. R.; GRACIOLI, Odacir D. Gerenciamento estratégico da informação por meio da utilização da inteligência competitiva e da gestão do conhecimento-um estudo aplicado à indústria moveleira do RS. Gestão \& Produção, v. 19, n. 4, p. 705-716, 2012.

ROBLES, José Manuel et al. The use of digital social networks from an analytical sociology perspective: The case of Spain. Rationality and Society, v. 27, n. 4, p. 492-512, 2015.

TEIXEIRA, Patrícia B. Caiu na rede. E agora? Gestão e gerenciamento de crises nas redes sociais. Digitaliza Conteudo, 2013.

VON KROGH, Georg. How does social software change knowledge management? Toward a strategic research agenda. The Journal of Strategic Information Systems, v. 21, n. 2, p. 154-164, 2012. DOI: 10.1016/j.jsis.2012.04.003. 
WHELAN, Eoin et al. Expanding the horizons of digital social networks: Mixing big trace datasets with qualitative approaches. Information and Organization, v. 26, n. 1-2, p. 1-12, 2016. DOI: 10.1016/j.infoandorg.2016.03.001.

YIN, Robert K. Estudo de Caso: Planejamento e Métodos. Bookman editora, 2015.

ZANCAN, Claudio; SANTOS, Paulo da C. F. Dos; CAMPOS, Vanessa O. As contribuições teóricas da análise de redes sociais (ARS) aos estudos organizacionais. Revista Alcance, v. 19, n. 1, p. 62-82, 2012. 